\title{
A MOEDA SOCIAL E O FORTALECIMENTO DO ESPAÇO DIFERENCIAL NAS PERIFERIAS
}

\section{THE SOCIAL CURRENCY AND THE STRENGTHENING OF THE DIFFERENTIAL SPACE IN THE PERIPHERIES}

\author{
Gustavo Resgala \\ Universidade Federal de Minas Gerais, Programa de Pós-Graduação em Arquitetura e Urbanismo, \\ Belo Horizonte, MG, Brasil
}

\begin{abstract}
R E S U M O : Este artigo compõe uma reflexão inicial de pesquisa que visa a explorar as relações entre pobreza urbana e desenvolvimento, abordando o processo de produção do espaço periférico urbano $\mathrm{e}$ a criaçâo de moedas sociais locais. A análise tem em vista a classificação de Lefebvre dos diferentes processos componentes da produção do espaço junto à distinção entre urbano enquanto processo socioespacial emancipatório e urbano industrial, advindo unicamente da lógica de industrializaçâo. Busca-se compreender a moeda social em seu potencial de questionar o sistema monetário (e demais aspectos da lógica hegemônica) e de promover alteraçôes locais nas relaçôes econômicas, sociais e políticas. Vislumbram-se, assim, possibilidades da demarcação de um território onde ganha força a diferença e a criatividade.
\end{abstract}

P A L A V R A S - C H A V E : periferias urbanas; moeda social; economia solidária; desenvolvimento endógeno.

A B S T R A C T : This article compiles an initial research reflection that aims to explore the relationship between urban poverty and development, addressing the production process of the urban suburb and the creation of local social currency. The analysis is based on Lefebure's classification for the different processes of the production of space together with the distinction between urban, as a process of social emancipation and urban industrial, which uniquely originates from industrial logic. The study attempts to understand social currency from within its potential to question the monetary system (and other aspects of hegemonic logic) and from promoting local changes in economic, social and political relations. Thus, the possibilities of demarcating an urban area where difference and creativity gain strength, grow within the context.

K E Y W O R D S : urban suburb; social currency; solidarity economy; endogenous development.

DOI: https://doi.org/10.22296/2317-1529.2017v19n2p267 


\section{INTRODUÇÃO}

1 Conceito utilizado por Singer (2009) ao tratar do processo de desenvolvimento do Bairro Conjunto Palmares (Fortaleza, CE) impulsionado pelas ações da associação de moradores local.

2 A referência utilizada de Lefebvre (1993), do livro The Productionof Space, foi, em sua maioria, lida na versão em processo de tradução por Doralice Barros Pereira e Sérgio Martins do Instituto de Geociências da Universidade Federal de Minas Gerais (IGC/UFMG).
O presente artigo compóe uma reflexão inicial de pesquisa mais ampla que pretende explorar as relaçóes entre pobreza urbana e desenvolvimento, abordando o processo de produção do espaço periférico urbano e a criação de moedas específicas de abrangência local - as moedas sociais -, enquanto iniciativas de endodesenvolvimento de áreas pobres ${ }^{1}$, ou seja, enquanto açôes provindas da própria sociedade civil, sem interferência direta de agentes exógenos, públicos ou privados. Ao utilizar-se de uma abordagem da produção do espaço, esta reflexão propóe alimentar o debate crítico, em curso no Brasil, sobre as disputas em torno da produção e do uso da cidade.

O caminho da discussão é estruturado tendo em vista a classificação de Henri Lefebvre (1993) ${ }^{2}$ dos diferentes processos componentes da produçáo do espaço urbano (espaço social, espaço abstrato e espaço diferencial), junto à distinção apresentada por ele entre urbano enquanto processo socioespacial emancipatório e urbano industrial, processo de produção do espaço advindo unicamente da lógica de industrializaçáo.

É, pois, lançada a questão: em que medida a circulaçáo de uma moeda social contribuiria para um processo de estruturação urbana de uma área? Levando para uma aplicação mais específica da ótica lefebrviana, a questão seria: em que medida a circulação de uma moeda social poderia significar o fortalecimento de um espaço diferencial - como descrito por Lefebvre - nas periferias urbanas?

De fato, este texto não tem o objetivo de responder tal questão e tampouco de propor aspectos verificativos dos resultados concretos de tais experiências. Oferece-se aqui, ainda que no campo das possibilidades, uma reflexáo teórica inicial dos possíveis potenciais das moedas sociais como construçáo do espaço diferencial, buscando destacar prováveis significados urbanos da instituição da moeda para além de um meio alternativo de compra e venda.

Assim, são evidenciados também aspectos de territorialidade em torno de tais experiências, entendendo que o estabelecimento de uma moeda social local pressupóe a pré-existência do local, ou seja, que haja coesão e relações urbanas já estabelecidas na área.

A base teórica do trabalho é fundamentada em dois autores principais, o filósofo francês Henri Lefebvre e o economista brasileiro Paul Singer. De Lefebvre, é aqui apropriada a discussão de produção do espaço enquanto alternativa de pensar o urbano abarcando suas complexidades. Já Paul Singer é referência nos estudos da economia solidária no Brasil e, mais propriamente, no acompanhamento da criação de moedas sociais no país nos últimos anos.

Também é acrescida nesse debate a visão do economista Celso Furtado em sua conceituação de desenvolvimento para além da ideia de crescimento econômico, e a do historiador econômico Karl Polanyi, que apresenta a problemática da naturalização e da autonomia dos fenômenos econômicos sobre as demais esferas da sociabilidade humana.

O artigo é composto, além desta Introdução, por mais quatro seçóes. O item seguinte trata das periferias urbanas e da produçáo social do seu espaço e apresenta conceitos de Henri Lefebvre relacionados a tal processo. Já a terceira seção apresenta a moeda social local e seus objetivos enquanto potencial alternativa à lógica monetária/ econômica hegemônica. O quarto item trata das possíveis relaçôes entre os signifi- 
cados da adoção de uma moeda social nas periferias e da ampliaçáo do horizonte de realização do urbano lefebvriano naquela realidade. Por fim, na última seção, são feitas consideraçôes a respeito dos limites da reflexão e é proposta uma agenda de pesquisa com novos enfoques para futuros estudos e inserçôes em campo dentro do tema abordado.

\section{AS PERIFERIAS URBANAS E O ESPAÇO DIFERENCIAL}

Conforme estudos da sociologia urbana, os problemas que permeiam a realidade da cidade - como segregação, adensamento e insalubridade - foram, a partir do surgimento da cidade industrial, potencializados e expandidos junto com a dinâmica de acumulação de capital ${ }^{3}$.

De fato, a lógica do capitalismo industrial é hegemônica nas cidades para além dos meios e espaços da produção, sendo fator determinante para todas as demais esferas da vida, isto é, para a reprodução das relações sociais, políticas, culturais etc. (LEFEBVRE, 2008; MONTE-MÓR, 2006b; SILVA, 2015). Sobre o processo histórico de apropriação da cidade pela indústria, Silva (2015, p. 236) aponta:

Ocorreu entấo um movimento duplo: a indústria tanto retorna às cidades quanto produz as suas próprias áreas urbanizadas; se apropria da cidade e a recria. Onde encontrou cidades antigas a indústria delas se apropriou intensamente. As cidades pré-existentes se expandem; surgem cidades operárias e subúrbios, surgem assentamentos precários. Onde a industrialização não ocupa ou fixa a mão de obra disponível proliferam cidades amputadas, dotadas apenas do indispensável à reprodução precária.

Há, portanto, uma nova dinâmica no processo de produção do espaço, que atinge inclusive o campo, estendendo no território as infraestruturas e as condiçóes gerais de produção relativas à produção e ao consumo para o mercado.

Temos, assim, ainda hoje, a lógica industrial exercendo forte influência na cidade, transformando o espaço em mercadoria e a urbanização, de forma hegemônica, em um processo de expansão fabril. Conforme aponta Silva (2015, p. 332): “Trata-se de perceber como a lógica da indústria penetrou profundamente na prática social e por isso mesmo pareceu tornar-se a única lógica possível, ocultando assim suas próprias limitações."

Monte-Mór (2001; 2006a; 2006b) constrói, a partir dos estudos do filósofo e sociólogo francês Henri Lefebvre sobre a origem e a definição da cidade, uma estruturação conceitual da cidade, composta pela tríade festa, poder e excedente, tratando, respectivamente, das dimensôes cultural (experiência coletiva), política e econômica da vida urbana. Se seguirmos nessa ótica, o capitalismo industrial, por constituir uma lógica de produção, acumulação e exploração da força de trabalho, acaba por produzir uma cidade que nega o urbano quando compôe espaços onde não há condiçôes para manifestaçóes políticas, culturais e apropriaçóes coletivas das riquezas ali geradas.

Marques (2005) classifica os diferentes tipos de capitais "concretos e específicos” que agem no cenário urbano, sejam aqueles que têm o espaço como secundário em
3 Para análises sobre como a indústria interfere historicamente na configuração urbana e em sua dinâmica, ver Mumford (2008). 
sua atividade produtiva ou aqueles formados pelos capitais produtores do ambiente construído, os quais têm o espaço como central no seu processo de valorização. Incluem-se neste último os capitais envolvidos com a promoção imobiliária, os capitais construtores de infraestrutura urbana e os envolvidos com a promoçáo de serviços urbanos. O autor indica, ainda, a necessidade de que sejam elaborados estudos específicos e detalhados sobre cada conjunto de atividades, pois, para ele, apenas o primeiro grupo (o capital imobiliário) encontra referente citação na literatura dos estudos urbanos. Já a classificação feita por Corrêa (1995) apresenta como agentes o Estado, os grupos excluídos da sociedade, os proprietários dos meios de produção (abordando, assim, a indústria), os proprietários fundiários e os promotores imobiliários (estes últimos englobando as nuances do capital imobiliário).

Partindo da compreensão de que a questão da propriedade privada integra o “jogo capitalista” (SINGER, 1979, p. 21), o mercado fundiário regula as distâncias sociais objetivadas na cidade, processo da produçáo espacial entendido como resultado da dominação social de classes. Sob este aspecto, revela-se a fundamental presença do Estado no processo de mercantilização fundiária através do provimento de serviços de infraestrutura urbana, instrumentos regulatórios e incentivos diversos que interferem no "valor" aferido à terra, o que, de certa forma, direciona a expansão urbana e reforça a espacialização das desigualdades sociais entre classes no território.

Bourdieu (1997) tem o território urbano como peça-chave nas disputas por apropriação de bens e serviços. A liderança na disputa pela localização no espaço urbano é determinada pela posse do capital, sob suas diferentes vertentes - capital social, cultural ou econômico-financeiro. Nesse sentido, aqueles desprovidos de capital se "assentam" em regiôes até entấo à margem dos interesses especulativos do mercado imobiliário, como as periferias urbanas, favelas e cortiços. São áreas predominantemente residenciais, marcadas ou pela irregularidade da ocupação ou nas quais os valores imobiliários são suficientemente reduzidos para serem suportados pelas populaçóes de baixa renda.

Para Lefebvre, a formaçáo do espaço periférico configura um processo de dominação burguesa que nega às classes inferiores o direito à cidade - um urbano sem festa, poder e excedente econômico (SILVA, 2015).

Sendo assim, temos aqui a ideia de periferização compreendida além de um lócus e de um processo dialético entre a hierarquia social e a configuração físico-espacial, com inflexôes também econômicas, políticas e culturais.

De inspiraçấo marxista, há uma visão consolidada da periferia definida como espaço da reprodução da força de trabalho, marcado por uma situação de carência e tido como socialmente homogêneo, sendo seus problemas resultado da ação negativa do Estado e do mercado de trabalho. Contudo, ainda que sintetize a dinâmica de periferização da moradia destinada a famílias de baixa renda, essa conceituação não esgota as possibilidades de constituição dos espaços periféricos que se tornam cada vez mais diversificados.

Desde meados da última década, tem ganhado espaço estudos que revelam uma complexidade muito maior da estrutura social urbana que a vista nos estudos clássicos. Se por um lado, os espaços exclusivos das camadas mais pobres são evidentes, por outro, a diversidade da estrutura socioeconômica e a complexidade de sua distribuição espacial continuam em crescimento. Sendo assim, embora o espaço urbano se mantenha marcadamente segmentado, as áreas periféricas revelam internamente 
a emergência de uma nova dinâmica entre moradia e trabalho, além de um relativo grau de heterogeneidade social (MARQUES; TORRES, 2005; LAGO, 2009; TONUCCI, 2009; ANDRADE, 2016).

Contudo, Andrade (2016) aponta que, ainda que haja uma crítica ao modelo centro versus periferia, baseada tanto no debate internacional quanto nas mudanças que tornaram o espaço urbano mais complexo socioespacialmente, isso não chega a significar o atual abandono das categorias centro e periferia nas análises urbanas. De fato, essas categorias são agora tratadas "não como pares exclusivos de uma ordem espacial, mas como territórios da metrópole” (ANDRADE, 2016, p. 102). Daí a pertinência, segundo a autora, de se tratar de periferias no plural, dada a sua maior diferenciação interna.

Dentre as denominaçôes analíticas que buscam ressaltar tais complexidades, tem sido empregado em diversos estudos o conceito de cidade fractal de Soja (2000). Tal sentido de fractalidade do tecido urbano leva em conta uma complexa reestruturação dos padrôes urbanos de polarização - fruto da combinação entre os novos processos de urbanizaçáo característicos da contemporaneidade capitalista e dos processos históricos de exclusão e segregação socioespacial - e vislumbra a cidade atual como um mosaico social urbano, "em uma geografia social fragmentada e polimorfa" (TONUCCI, 2009, p. 2).

Em geral, as análises urbanas atuais no país acabam por evidenciar novas e diferentes formas de organização das diversidades urbanas e desigualdades sociais, figurando, inclusive, algumas formas em que há intensificação da segregação e de conflitos frente à complicada proximidade dos diferentes grupos sociais (ANDRADE, 2016; TONUCCI, 2009).

Adiciona-se a isso a visão de Costa (2003) e Topalov (1988), pela qual, frente às diversas leituras da dinâmica urbana e regional que marcaram as últimas décadas, fica a impressão de que estamos presenciando um momento de crise no pensar a cidade. Essa situação de incertezas, segundo Costa (2007, p. 6), teria como um dos aspectos os "questionamentos em torno da suficiência dos paradigmas críticos de orientação estruturalista e marxista em dar resposta à complexidade dos fenômenos socioespaciais urbanos."

Há de se considerar que as análises urbanas de cunho estruturalista e marxista introduziram importantes avanços no conhecimento do processo urbano no capitalismo. No entanto, o enfoque economicista da economia política tem como desvantagem, segundo Fainstein (1997, p. 23), "a negaçâo da validade de percepçôes subjetivas que orientam o comportamento humano” e, segundo Gottdiener (1993, p. 370), o fato de desconsiderar "a importância que a dimensão espacial tem para a análise dos fenômenos urbanos".

Une-se a tais questionamentos a reestruturação econômica mundial, que evidencia o fim do objeto de estudo das análises estruturalistas: a "metrópole fordista keynesiana", um "produto" tido como acabado, que se dissipa junto com a suficiência das ideias que se ancoravam em suas dinâmicas (COSTA, 2003).

De fato, no Brasil, assim como nos demais países periféricos do mundo capitalista, a lógica de produção fordista (junto ao Welfare State) produziu cidades por processos sumariamente diferentes dos vislumbrados nos países centrais. Além de serem direcionados a partes do Brasil (concentrando os investimentos no eixo sudeste-sul e gerando disparidades regionais em níveis altíssimos), no interior das cidades os padróes do 
4 Mesmo com tais diferenças, a administração urbana no mundo subdesenvolvido tenta, ao máximo, fazer com que as megacidades se assemelhem aos moldes da cidade global. E isso se faz essencialmente garantindo a "invisibilidade" dos pobres, à medida que se esconde as favelas e as periferias (CANETTIERI, 2014).
5 LEFEBVRE, H. Space: social product and use value. In: FREIBERG, J. (Ed.). Critical Socilogy: European perspective. New Yor: Irvington Publishers, 1979. urbanismo desenvolvimentista foram aplicados a restritas porçóes urbanas, formando verdadeiras "ilhas de primeiro mundo" cercadas de um mar de pobreza e precariedade, constituído por favelas, cortiços e loteamentos clandestinos (MARICATO, 2009).

Se, na maioria das metrópoles dos países desenvolvidos, o mercado (esfera dominante de acesso aos recursos) convive com a redistribuiçáo realizada pelos regimes de bem-estar social que se implantaram naqueles países, nos países periféricos, diferentemente, esse processo foi incompleto, e a precária acumulação prévia à industrialização demandou a formação do setor informal e de uma urbanização precária e desigual. (MENDONÇA; ANDRADE; DINIZ, 2015, p. 18).

Ainda assim, as mudanças decorrentes do fim do modelo fordista e intensificação do processo de globalização conformaram um tipo diferente de cidade nos países periféricos (as megacities) se comparado aos efeitos desses processos na conformação das globalcities dos países centrais. As megacities, como são definidas pela literatura urbana, caracterizam-se por uma urbanização dispersa, com expressivo crescimento essencialmente demográfico - não necessariamente econômico e tecnológico -, apresentando graves problemas sociais, com forte incidência de pobreza e altas taxas de violência ${ }^{4}$.

A proposta deste texto de utilizar as contribuiçóes do pensamento filosófico de Henri Lefebvre visa a avançar no olhar sobre a cidade. A visão lefebvriana de cidade e regiâo enquanto espaços socialmente produzidos vai além da condiçấo de um produto (o ambiente construído), para uma noção de processo: obra de uma contraditória relaçáo entre os diferentes agentes construtores da vida urbana. Para Lefebvre, além de ser meio de produção, o espaço é também um meio de controle e, portanto, de dominação, de poder (LEFEBVRE, 1993).

A ótica eminentemente espacial da teoria lefebvriana evidencia uma natureza unitária para a cidade que abrange diversos aspectos econômicos, políticos e sociais, que são ou negligenciados ou não trabalhados em conjunto por outras teorias urbanas. $\mathrm{Na}$ busca por abrangermos as complexidades inerentes aos processos urbanos, o pensamento filosófico de Henri Lefebvre leva-nos à compreensáo da composição urbana enquanto um sistema de layers, onde diferentes processos de produção do espaço se sobrepóem e se misturam, visão esta que legitima os conflitos e contradiçóes característicos da realidade da cidade.

Apresento os tipos de espaço de Lefebvre pela metáfora do sistema de layers entendo-os em um funcionamento semelhante a um software de desenho gráfico ou de geoprocessamento, pelo qual é possível sobrepor camadas com ferramentas de transparência, mesclas de seus atributos, ou até de ocultar certos elementos, conforme o que se deseja para a análise. Assim, conforme o ponto de vista da análise, é possível, para um mesmo espaço geográfico, serem evidenciados diferentes processos que configuram ali diferentes tipos de espaços. Lefebvre classifica os processos de produção do espaço conforme os agentes que ali atuam e seus diferentes interesses.

O filósofo utiliza-se do conceito de espaço social, que se refere ao espaço de apropriação da vida social, "ou espaço de valores de uso produzido pela complexa interação de todas as classes na procura da vida cotidiana" (LEFEBVRE, 1979, p. $290^{5}$ apud COSTA, 2003, p. 12); e também do conceito de espaço abstrato, ou espaço da expropriação, comandado pela lógica da produção e acumulação capitalista: "Esse 
espaço [espaço abstrato] formal e quantificado nega as diferenças, as que provêm da natureza e do tempo (histórico), assim como as oriundas do corpo, idades, sexos, etnias. (LEFEBVRE, 1993, p. 49, tradução nossa).

Nesse sentido, as relaçôes socioespaciais são tomadas dialeticamente como produtor e produto, e a relação entre valor de uso e valor de troca produz, ao mesmo tempo, um espaço social de usos e um espaço abstrato de expropriaçáo. Das contradiçôes inerentes ao espaço abstrato, surge o chamado "espaço diferencial" que, baseado no conceito de diferença, busca resistir ao poder de homogeneização da lógica de acumulaçãa ${ }^{6}$.

O conceito lefebvriano de diferença não se baseia nas particularidades individuais, "mas nas diferenças que emergem de um processo de luta". Dessa forma, com o foco na luta cotidiana, esse conceito náo se enquadra nas diferenças em termos étnicos e de gênero, mas sim frente às relaçôes homogeneizadoras impostas pela dinâmica capitalista, que reduz o espaço social (de usos) a um espaço abstrato de expropriação (de trocas) (COSTA; COSTA, 2005).

Também outra relação pode ser feita a partir da abordagem do sociólogo espanhol Manuel Castells (1999) do processo de construção social da identidade ${ }^{7}$. Mesmo que seu estudo não abarque a dimensão espacial proposta neste trabalho ${ }^{8}$, sua classificação das formas e origens de construção de identidades também evidencia as contradiçôes inerentes à dinâmica urbana. $\mathrm{O}$ autor classifica como identidade legitimadora a que é "introduzida pelas instituiçôes dominantes da sociedade no intuito de expandir e racionalizar sua dominação em relaçâo aos atores sociais" (CASTELLS, 1999, p. 24), e, portanto, entendo que esse padrão social (assim como o "padrão" lefebvriano espacial da expropriação) promove a manutenção das desigualdades socioespaciais: uma homogeneização que elimina, de forma avassaladora, as diferenças e as possibilidades de emancipação social.

Concordo que há riscos em adicionar à discussão da importância do fator espacial a contribuição de Castells, já que este, conforme Gottdiener (1993), ignora a dimensão territorial/espacial na análise da cidade. Porém, na busca por parâmetros que evidenciem um caminho de confronto às contradiçóes presentes na cena urbana, encontramos o que o autor destaca como "identidade de resistência".

Para Castells (1999, p. 24), a visão de uma força de resistência (identidade de resistência) a esse processo provém "de atores que se encontram em posiçóes/condiçôes desvalorizadas e/ou estigmatizadas pela lógica da dominação". Esse padrão teria como base "princípios diferentes dos que permeiam as instituiçôes da sociedade, ou mesmo opostos a estes" (CASTELLS, 1999, p. 24).

Utilizo tal abordagem no entendimento de que, se os princípios, conforme apresentado na citação acima, estiverem focados nas contradiçôes inerentes ao processo capitalista, teríamos, assim, a produção de um espaço diferencial, pois, segundo a égide lefebvriana, "nenhuma revolução social pode ter êxito sem ser ao mesmo tempo uma revoluçấo conscientemente espacial" (SOJA, 1993, p. 116).

Tendo por alicerce o pensamento de Lefebvre e com a contribuição de Castells, busco, assim, as bases para a inserção da perspectiva espacial na análise dos possíveis significados da criação de uma nova moeda de circulação restrita em uma área periférica. $\mathrm{O}$ item seguinte faz uma breve reflexão da moeda social enquanto potencial instrumento de desenvolvimento econômico local alternativo à lógica financeira oficial, sendo depois proposta uma interpretação espacial (ou lefebvriana) de seus possíveis efeitos e significados.
6 Tendo como base 0 potencial de emancipação social, este espaço encontra na vida cotidiana seu agente produtor, com o objetivo de "resgatar o valor de uso do espaço da tendência em transformá-lo unicamente em valor de troca" (COSTA 2003, p. 13).

7 No que diz respeito a atores sociais, Castells (1999, p. 22) define o conceito de identidade como sendo "o processo de construção de significado com base em um atributo cultural, ou ainda um conjunto de atributos culturais inter-relacionados o(s) qual(ais) prevalece $(\mathrm{m})$ sobre outras fontes de significado".

8 Para as devidas ressalvas frente às divergências entre as teorias de Castells e Lefebvre, ver Soja (1993) e Gottdiener (1993). 


\section{A MOEDA SOCIAL E O ENDODESENVOLVIMENTO NAS PERIFERIAS}

9 Pesquisa realizada pela Federação do Comércio do Estado do Rio de Janeiro (Fecomércio-RJ) e pelo Instituto Ipsos. A sondagem foi feita no mês de abril de 2015 com 1.200 consumidores, em 72 municípios do país.

10 Mesmo que esse índice revele, conforme a pesquisa, o menor percentual em nove anos no país, indicando um paulatino crescimento no que tem sido denominada de taxa de bancarização da população, ainda assim os $36 \%$ representam um maciço populacional de 48,5 milhões de brasileiros sem acesso ao sistema bancário.

11 Paul Israel Singer é economista e professor da Universidade de São Paulo (USP), tendo sido titular por 13 anos (de junho de 2003 a junho de 2016) da Secretaria Nacional de Economia Solidária (SENAES) do Ministério do Trabalho e Emprego do Governo Federal.
Conforme dados de $2015^{\circ}$, 36\% da população no país não tinha acesso a serviços financeiros oficiais, seja por bancos públicos ou privados ${ }^{10}$. Tal exclusão desses muitos brasileiros se deve tanto pela falta de renda dessas pessoas, pela realidade informal de trabalho, por morarem em áreas irregulares (como favelas e "ocupaçōes"), quanto pela ausência de documentos, dentre outros - além de se verem integrados a comunidades em que quase a totalidade dos membros está na mesma condição.

Paul Singer (2009), referência no estudo e acompanhamento ${ }^{11}$ das experiências de economia solidária no Brasil, faz a classificação do sistema financeiro como que composto por 3 partes:

I. uma parte capitalista, formada por intermediários financeiros - bancos, companhias de seguro, corretoras etc. - que têm por objetivo fundamental o lucro, mais precisamente o maior retorno sobre o capital investido. II. outra parte é estatal, composta por bancos federais e estaduais, que não deveriam visar lucro, mas a prestação de serviços ao público. E III. uma grande variedade de intermediários financeiros, parte dos quais poderia ser chamada de social ou solidária, composta por bancos e outros intermediários financeiros privados que não visam lucro, mas o atendimento das necessidades de comunidades excluídas do acesso aos serviços das outras duas partes. (SINGER, 2009, p. 69).

Nesse terceiro grupo, além dos arranjos de cunho social ou solidário, há instituiçôes que, ao contrário, visam à maximação dos lucros no atendimento das comunidades, como agiotas e empresas comerciais de empréstimos ou de sorteio de prêmios voltadas à baixa renda.

Singer (2009) denomina como instituiçôes financeiras sociais ou solidárias aquelas que não visam ganhos pecuniários para si, abrangendo as entidades de microcrédito-EMCs, que atuam com fontes estatais ou internacionais, e as associaçôes de poupança e crédito, como as cooperativas de crédito, que atuam com fundos rotativos alimentados pelos sócios locais. Há também a configuração de Clubes de Troca, que são associações autogestionárias que utilizam moedas sociais específicas para a circulação local.

De fato, o termo "finanças" refere-se à utilização do dinheiro e, em geral, a todas as atividades que conformam o fluxo monetário de entrada e saída ao longo do tempo. Contudo, segundo Muñoz (2009), tal conceituação não faz qualquer referência a quem sejam os atores envolvidos, os objetivos almejados, etc., "preocupações estas que se fazem necessárias ao apontar-se que, em seu desenvolvimento 'normal', as finanças hegemônicas captam recursos de muitos para gerar crescente concentração e centralização entre poucos" (MUNÓZ, 2009, p. 208). Nesse sentido, as finanças solidárias conformam-se como uma resposta a essa lógica, pois visam democratizar os recursos financeiros a operar a serviço das necessidades da população com base em princípios como a ética e a solidariedade, e priorizando o atendimento aos excluídos do sistema bancário tradicional (MUÑOZ, 2009; COELHO, 2003).

Ademais, as instituiçóes financeiras solidárias inserem-se no campos das práticas de economia solidária, e preveem, antes de mais nada, viabilizar suporte financeiro aos empreendimentos desse modelo econômico. 
A economia solidária no Brasil tem se conformado com um conjunto de unidades produtivas organizadas coletivamente e de forma autogestionária - por princípios socialistas ou cooperativistas - e que são assessoradas pelos movimentos sociais de economia solidária - concentrados no Fórum Brasileiro de Economia Solidária junto à Secretaria Nacional de Economia Solidáriai2 ${ }^{12}$ (SENAES).

De fato, tendo sido a SENAES coordenada pelo professor e economista Paul Singer, a efetivaçáo das políticas e práticas no país acabaram por se moldar conforme suas conceituaçóes, manifestas em seus estudos ${ }^{13}$.

O campo das finanças solidárias no Brasil é formado por 03 segmentos: Fundos Solidários, Cooperativas de Crédito e Bancos Comunitários.

No caso dos Bancos Comunitários aqui destacados, suas açôes se concentram não somente na viabilização de suporte financeiro e operacional aos empreendimentos vinculados à economia solidária, mas também atuam no apoio financeiro às comunidades pobres em seus produtores, prestadores de serviço, comerciantes e seus consumidores. Ou seja, além de operarem com microcrédito, buscando atuar junto a comunidades (e não apenas a microprodutores, como é mais comum), também, em muitos casos, os bancos funcionam como clubes de troca solidários, tendo como propósito criar um mercado para um pequeno grupo, podendo, contudo, se expandir para bairros inteiros.

Esse é o caso da experiência do Banco Palmas no Conjunto Palmeiras em Fortaleza, o primeiro, segundo Singer (2009), a projetar um Clube de Trocas que em princípio tem como sócios os 35 mil habitantes do Conjunto (e mais moradores em bairros próximos), operando a partir da circulação de uma moeda local - a moeda Palmas, que circula desde o ano 2000.

O Conjunto Palmeiras teve seu início na década de 1970, como resultado de uma política de remoção e realocação da população que habitava em áreas de risco ou em áreas litorâneas da capital. Cerca de 1.500 famílias foram levadas para a área do conjunto sem qualquer infraestrutura urbana e localizada a uma distância de 22 quilômetros do centro comercial de Fortaleza, um "terreno alagadiço coberto por mato e lama" (TAFURI, 2014, p. 54).

De fato, políticas públicas de "desfavelamento" como essa eram comumente implantadas nas grandes cidades na década de 1970 e, além de promoverem uma liberação de áreas de interesse do capital imobiliário, configuravam-se em uma forma de "sanear" a paisagem urbana de áreas tidas como insalubres e violentas.

A retirada da populaçáo pobre, que habitava irregularmente áreas litorâneas da capital, e a sua realocação em uma região distante, revela a dinâmica pela qual são excluídos da cidade aqueles incapazes de "pagar" por ela. Esse processo acompanha o movimento imposto pela dinâmica imobiliária que faz com que aqueles com renda inferior, não conseguindo ter acesso formal a terrenos em áreas mais centrais, são direcionados às áreas periféricas, onde encontram preços acessíveis à sua renda. Já no caso dos moradores de áreas de vilas e favelas, que têm na ocupaçáo irregular a forma de habitarem próximos a regiōes mais valorizadas, o seu deslocamento às áreas periféricas é imposto pela atuação direta do Estado.

Conforme a visão de Bourdieu (1997), apresentada no item anterior, a posse de capital determina a capacidade de dominar o espaço urbano, permitindo manter à distância "as pessoas e as coisas indesejáveis ao mesmo tempo que aproximar-se de pessoas e coisas desejáveis” (BOURDIEU, 1997, p. 163). Dessa forma, o processo

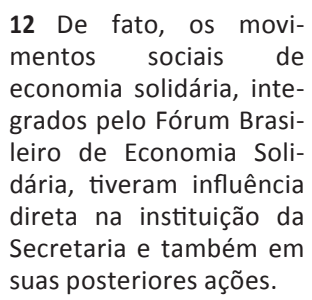

13 Ver Singer (2000; 2002). 
das disputas pela localização territorial a partir da posse de capital une-se à visão da produção do espaço abstrato lefebvriano que busca dominar a dinâmica urbana (LEFEBVRE, 1993).

Nos anos subsequentes ao início do Conjunto Palmeiras, a área teve um crescimento populacional expressivo, principalmente em virtude da abertura de novos loteamentos populares em 1979 (NASCIMENTO, 2011). Ademais, junto ao processo de crescimento populacional, as décadas de oitenta e noventa caracterizaram-se por mobilizaçôes coletivas dos moradores em prol de melhorias na infraestrutura urbana do bairro, concentradas nas açôes da Associação dos Moradores do Conjunto Palmeiras (ASMOCONP).

Tendo em vista as benfeitorias urbanas implantadas no bairro, a partir do final dos anos 1990 a associação dos moradores passou a buscar, então, açôes voltadas às melhorias nas condiçóes de renda da comunidade. Isso se deu com base na constatação de que diversos moradores estavam vendendo seus imóveis e se mudando para bairros periféricos mais distantes ou em áreas de risco por náo terem condiçóes financeiras para arcar com os custos dos serviços públicos advindos do processo de urbanização do bairro (taxas de água, luz, esgoto, telefone, etc).

As iniciativas de melhoria de renda concretizaram-se na criação do Banco Palmas em 1998 objetivando, dentre outras açóes, o fornecimento de microcrédito para a produção e consumo da população, e a criação, em 2000, da moeda local Palmas, prevendo um incentivo para que o consumo dos moradores pudesse se concentrar no comércio e nos serviços do próprio bairro. De fato, em uma pesquisa que antecedeu a criação do banco na qual foi mapeada a produçấo e o consumo da comunidade, foi constatado que

[...] os 30 mil habitantes do Conjunto Palmeira gastavam mensalmente o montante total aproximado de $\mathrm{R} \$ 1.500 .000,00$, ou seja, que o bairro não era pobre porque não tinha dinheiro, mas sim devido à perda da base monetária local provocada pelo consumo realizado quase que exclusivamente fora do bairro, nos grandes centros comerciais (MELO NETO SEGUNDO; MAGALHÁES, 2003 apudTAFURI, 2014, p. 54).

Após mais de 10 anos de funcionamento do banco e de circulação da moeda, um estudo realizado pelo Núcleo de Economia Solidária da Universidade de São Paulo (NÚCLEO DE ECONOMIA SOLIDÁRIA, 2013) apontou consideráveis melhorias no Conjunto Palmeiras nas áreas de oportunidade de emprego, educação e acesso a serviços financeiros. Contudo, a pesquisa evidenciou também o passivo social ainda presente na realidade do bairro.

Tem-se, assim, na inicial configuraçáo espacial dessa área e no seu subsequente processo de expansão populacional, a consolidação de um padrão precário de crescimento urbano ditado pela lógica abstrata de um mercado de terras. Por outro lado, as iniciativas coletivas que se iniciaram na provisão de infraestrutura urbana e que cresceram em escopo na criação do banco e das açóes a ele vinculadas revelam, assim, um processo de desenvolvimento em novos moldes, onde a diversidade, a criatividade

14 Ganham destaque os estudos vinculados ao Centro de Estudos Sociais (CES) da Universidade de Coimbra, Portugal, e os trabalhos do Instituto de la Moneda Social, na Espanha. e os laços comunitários se tornam o fundamento para a criação endógena das respostas aos problemas da vida cotidiana.

De fato, tem sido referência para os estudos no Brasil, sendo também abordada em análises internacionais ${ }^{14}$, a inovação da experiência do Banco Palmas de adicionar uma moeda social ao modelo de microcrédito solidário. 
A moeda social possibilita identificar o quanto uma ação de economia solidária é capaz de abranger toda uma área urbana (e não apenas um pequeno grupo de adeptos). De fato, a moeda configura um potencial de extensa abrangência e adesão pela população na medida em que viabiliza a conformação de um extenso clube de trocas em toda a área delimitada como de atendimento do banco comunitário.

A fim de fomentar o uso da moeda e fidelizar a clientela do bairro, o Banco sugere aos comerciantes locais que ofereçam desconto no preço das mercadorias quando a compra é paga em Palmas: "Esse acordo fez com que um volume acrescido de compras dos moradores tenha se concentrado nas lojas, mercearias, quitandas etc. no Grande Jangurussu, beneficiando não só o comércio, mas também as unidades de produção lá estabelecidas." (SINGER, 2013, p. 37).

A partir de 2005, houve um apoio do governo federal, por meio de convênio com o Banco Palmas, para a disseminaçấo da metodologia dos bancos comunitários pelo país ${ }^{15}$, conformando a Rede Brasileira de Bancos Comunitários, composta por 116 bancos em 19 estados (incluindo o Distrito Federal) e a criação, no fim de 2015, de uma associação em formato de Organização da Sociedade Civil de Interesse Público (OSCIP) denominada Banco Nacional das Comunidades, tratando-se do conjunto dos Bancos Comunitários de Desenvolvimento do país.

De fato, ainda que a Rede Brasileira de Bancos Comunitários procure aplicar uma mesma metodologia que foi criada e é coordenada pelo Instituto Palmas em Fortaleza às experiências de circulação de moedas locais, cada experiência acaba por revelar dinâmicas e propósitos especiais para os quais foi criada, "posto que nasce da própria comunidade e é um processo de constante construção" (MENEZES, 2007, p. 48). Assim, tendo em comum a delimitação espacial em sua circulação, as iniciativas de instituiçáo de moedas sociais revelam especificidades locais que acabam por permitir que muitos aspectos de análise, como é o caso do regime legal e regulatório abordado pela tese de Freire (2011), estejam ainda em aberto ${ }^{16}$.

Segundo o estudo de Freire (2011), o adequado funcionamento das moedas sociais está sujeito a diversas circunstâncias "de fato e de direito" presentes nas realidades sociais em que são implantadas. Ainda, como as moedas se apresentam com diferentes denominações e formas jurídicas, diversos fatores legais e regulatórios continuam abertos e em discussão em quase todas as instâncias jurídicas. Contudo, a autora concentra-se em aspectos frente à liberdade de associação e à liberdade de contratar inerentes às moedas para evidenciar algumas possíveis formas de organizá-las e estruturá-las juridicamente.

[...] as moedas sociais podem ser convenientemente organizadas sob as categorias do direito das obrigaçóes e do direito dos contratos (Lei 10.406, de 2002) e podem ser estruturadas de formas simultaneamente compatíveis com a política monetária sob a responsabilidade do Banco Central (art. 164 da CRFB), a regulamentação bancária (art. 192 da CRFB; Lei 4.595, de 1964), as normas do sistema de pagamentos brasileiro (Lei 10.214, de 2001) e as políticas públicas direcionadas à concretização dos objetivos fundamentais da República Federativa do Brasil (art. $3^{\circ}$ da CRFB). (FREIRE, 2011, p. 7).

Já este artigo visa a levantar outra possível compreensão na análise da circulação de uma moeda social, que é a ótica espacial de seus possíveis efeitos e significados. Ou seja, a busca por evidenciar na adoção de um sistema monetário de base local e social
15 Esse apoio aos bancos comunitários coincide com o período de consolidação (e divulgação de resultados positivos) do programa federal de transferência direta de renda Bolsa-Família. Temos, assim, o aumento no poder de compra da população de baixa renda, combinandose com a promoção de um sistema financeiro moldado às condições dessa população.

16 Dentre os demais estudos, referencio Soares (2006), que faz uma análise comparativa das moedas sociais no Brasil que são vinculadas aos bancos comunitários e, também, de moedas sociais em outros países que são geridas por outros mecanismos; e Menezes (2007), Santos e Silva (2014) e Rigo (2014), que analisam a moeda social sob a ótica da exclusão e emancipação social. 
17 LEE, R. Local money: geographies of autonomy and resistance? In: MARTIN, R. Money and space economy. New York: Wiley\& Sons, 1999. p. 207-224.

18 "Miguel" Yasuyuki Hirota é pesquisador japonês da Universidade de Valência, Espanha, e colaborador do Instituto de la Moneda Social, tendo atuado na promoção e investigação de moedas sociais em 23 países/regiões (incluindo o Brasil). (entendendo que está a serviço das comunidades que as criam e implementam) os aspectos de produção de um espaço diferencial frente à abstração, que é hegemônica na produção das cidades e metrópoles.

Tem-se em vista que, grosso modo, a moeda social visa a se configurar como um acordo feito entre pessoas de uma comunidade para o uso de um meio de pagamento restrito ao espaço onde vivem (um incentivo para o consumo local) e que é coexistente com a moeda nacional. Em sua pesquisa, Menezes (2007) utiliza a afirmação de Roger Lee de que a moeda é o mais geográfico dos fenômenos econômicos, ao passo que permite a produção econômica e a reprodução social no tempo e no espaço (LEE, $1999^{17}$ apud MENEZES, 2007).

Assim, a reflexão deste artigo busca evidenciar aspectos que sugerem a moeda social como uma proposta de (re)enraizar a moeda no território, à medida que promove uma dinâmica de autogestão, ou seja, de autonomia de um grupo sobre as riquezas geradas por ele. Ainda mais, propôe-se destacar fatores que vislumbrem em tais experiências uma alternativa à lógica hegemônica de produção e reprodução da qual se compóe o sistema financeiro-monetário oficial - equivalente ao espaço abstrato, genérico, desenraizado -, para uma moeda de base local. Deixe-se assim, para trabalhos futuros, a tarefa de dialogar criticamente com discursos que consideram a moeda social como impressa por relaçôes não capitalistas, conforme defendido pelos adeptos da economia popular e solidária.

O escoamento da moeda pode se dar por empréstimos concedidos pelos bancos comunitários, pelos trocos em moeda local dados pelos vendedores, por pagamento de parte do salário de funcionários locais conforme comum acordo e, mais comumente, pela troca nos bancos comunitários de reais pela moeda local por qualquer interessado nos descontos oferecidos pelos comerciantes e produtores locais. Assim como outras açôes de desenvolvimento denominadas solidárias, a moeda social é dependente da confiança e adesão da comunidade para seu funcionamento. Nesse sentido, à circulação da moeda precede a existência de uma coesão urbana entre os moradores que evidencie já a necessidade de desenvolvimento local e de reter as riquezas ali geradas. Ademais, Hirota $^{18}$ (2016) tem o fortalecimento da coesão não apenas como um pré-requisito, mas também como uma meta, um objetivo social fundamental das moedas sociais pelo mundo: "Un hecho destacable es que el éxito de diferentes monedas sociales se basa en el lazo fomentado a lo largo de muchos años entre los sócios" (HIROTA, 2016, n.p.).

Podemos adicionar à constatação da coesão urbana, que prefigura e objetiva a criação da moeda, os conceitos de territorialidade e regionalismo trabalhados por Markusen (1981). A autora define regionalismo como sendo "reivindicação política de um grupo de pessoas identificado territorialmente contra um ou muitos mecanismos do Estado" (MARKUSEN, 1981, p. 83). Essa caracterização faz do regionalismo um fenômeno composto pelas relações sociais entre um grupo e outro de pessoas - e não de um lugar com outro lugar -, além de possibilitar o uso da qualificação territorial que os distingue, de forma a identificar uma "arena" de luta: "uma arena política - mesmo que o conteúdo da luta seja econômico ou cultural” (MARKUSEN, 1981, p. 83). Assim, a diferenciação territorial, resultante de possíveis diversidades econômicas e culturais entre populaçóes, não é, necessariamente, base para a definição regional ou para a luta regional, "[a] menos que a diferenciação resulte de, ou constitua, a base para alguma forma de opressão, a variação regional na cultura humana e na estrutura econômica não provocará, necessariamente, reivindicaçôes regionais conflitivas com o Estado." (MARKUSEN, 1981, p. 84). 
A contribuição de Markusen ao fenômeno aqui estudado permite-nos, então, vislumbrar possibilidades de ter na moeda circulante local a expressão de um regionalismo emergente, ou melhor, de uma reivindicação territorial contra os mecanismos responsáveis pela opressão política (mesmo que com conteúdo claramente econômico) vivida pela comunidade local ${ }^{19}$.

Entende-se que a precedência de um conflito regional é o que justificaria a instituição do banco comunitário, bem como a demarcação de sua área de abrangência, sobretudo em relação ao território em que circulará a moeda social. Ademais, tal regionalismo possibilita vislumbrar o potencial de adesão da população local, fator essencial no êxito da nova moeda.

Tendo por base o caminho de reflexão feito até aqui, e estando este unido à ideia - que é em primeira instância de cunho político - de criação da moeda local pela (e para a) comunidade, é possível identificarmos sua instituição como fruto de açôes questionadoras da comunidade local em relação à lógica econômica convencional. Esta hipótese nos possibilitaria, então, vislumbrar um possível fortalecimento de um espaço diferencial nas áreas pobres urbanas frente à lógica padronizadora e abstrata, não apenas do mercado, mas das demais formas de produção e reprodução hegemônicas.

Coraggio (2000) define como reprodução ampliada da vida a busca da melhoria progressiva na qualidade de vida em seus diversos aspectos. Esse termo é amplamente utilizado para designar as perspectivas de prosperidade dos membros de empreendimentos solidários, consistindo assim, em um caminho diferencial, em contraponto tanto à busca pela acumulaçáo do capital, pelo lucro, quanto ao mantimento da vida com o mínimo, a busca pela sobrevivência - designada por Coraggio como reprodução simples da vida.

Para melhor aplicar a relação da moeda social no fortalecimento do espaço diferencial nas periferias, uso da categorização feita por Fuller e Jonas $\left(2003^{20}\right.$ apud MENEZES, 2007) frente às finalidades e práticas adotadas por instituiçôes ${ }^{21}$ como os bancos comunitários ao se constituírem em alternativas à lógica vigente. Eles propõem três categorias:

i) alternativas-opositoras, que seriam as instituiçôes cujo propósito é a construção de valores e normas diferentes e negadoras da tendência dominante; ii) alternativas-suplementares, que seriam antes uma opção adicional do que uma escolha de contrapor-se à hegemonia; e iii) alternativas-substitutas, que ocupam espaços vazios ou antes ocupados por instituiçóes convencionais. (MENEZES, 2007, p. 13).

À medida que se compreende que o espaço diferencial produzido náo necessariamente deva evidenciar um enfrentamento ao capitalismo hegemônico, mas sim um movimento social que busca uma forma alternativa de vida política e econômica, podemos compreender, assim como a pesquisa de Menezes (2007), que as experiências no Brasil dos bancos comunitários se configuram ao mesmo tempo em alternativas suplementares e substitutas. Por esse viés, surge o questionamento de se as moedas sociais seriam capazes de compreender uma nova opção mercantil frente à convencional, mesmo que sem ocorrer um enfrentamento a esta (tendo a moeda social lastro no real) e se elas podem também ocupar os espaços vazios que o sistema convencional não ocupa (seja por não ter interesse ou por não ser capaz de atuar).
190 termo opressão referese a quando um grupo controla um conjunto de instituições que determinam o conteúdo da experiência humana, à custa de outro grupo (MARKUSEN, 1981, p. 68)

20 FULLER, D.; JONAS, A. Alternative financial spaces. In: LEYSHON, A.; LEE, R.; WILLIAMS, C. C. (Ed.). Alternative economic spaces. London: Sage, 2003. p. 55-73.

21 Os autores abordam os Local Employmentand Trade Systems (LETS), tidos como pioneiros na formulação de clubes de trocas e moedas sociais, que tiveram seu início no Canadá, nos anos 1980 e foram disseminados na Inglaterra, Escócia, Noruega, Finlândia, Bélgica, Holanda, França, Austrália e Nova Zelândia. 
22 Utilizo o conceito trabaIhado por Furtado (1978) de desenvolvimento como sendo a expressão da capacidade para criar soluções para problemas específicos, diferente da ideia de crescimento econômico.

23 Conceito utilizado por Singer (2009) ao tratar do processo de desenvolvimento de um bairro impulsionado por ações da própria sociedade civil, sem interferência direta de qualquer agente exógeno, público ou privado.
De fato, à medida que uma área urbana é delimitada para receber uma forma de relacionamento de compra e venda de produtos e serviços, que a diferenciam do restante da cidade, pode-se notar que a lógica oficial do mercado de livre concorrência não atende às necessidades e potencialidades locais daquela área. Ademais, sob a ótica da produção do espaço, apresentada no item anterior, pode-se ainda perceber ser a lógica oficial do mercado e das demais formas de produção e reprodução capitalistas a responsável por uma legitimação da situação precária da área urbana em questão.

Nesses termos, a ideia de desenvolvimento local ${ }^{22}$, ou desenvolvimento endógeno, ou ainda endodesenvolvimento ${ }^{23}$, defendida pelos bancos comunitários pode ser entendida aqui também como a proposta de uma reestruturação urbana na área em questão. Reestruturação urbana não no sentido restrito de promoção de infraestrutura ou de serviços públicos, mas sim em relação ao conceito de urbano trabalhado por Lefebvre, que trata do processo que conduz à emancipaçáo da sociedade e que modifica as tendências da lógica industrial - sobretudo referente à força de redução das diversidades, ou seja, da homogeneização do espaço abstrato. Na desejada efetivação desse horizonte, que pode ser denominado de urbano utópico, a tríade festa, poder e excedente enfim se realizaria.

Assim, no item seguinte, busco evidenciar a circulação da moeda social de uma área periférica urbana frente a seu possível significado de fortalecimento do espaço diferencial, ou seja, de indutor de um processo de desalienação de uma população da lógica capitalista oficial.

\section{O DESENVOLVIMENTO LOCAL E O ESPAÇO URBANO DA DIFERENÇA}

O termo alienação é aqui abordado sob a ótica de Marx investigada por Ollman (1976), que trata o conceito como sendo elemento central do trabalho e da produção do capitalismo - relacionando a produçáo de bens e o processo de mercantilização expandido às relaçôes sociais e à vida. Assim, tem-se aqui a alienação social como um estado coletivo ou individual em que é eliminado o senso de participação política, de questionamento da lógica hegemônica, de pensamento crítico - no qual se passa a aceitar tudo o que é dado como algo natural, racional ou divino. Nesse sentido, temos a alienação como fenômeno do processo homogeneizador de produção do espaço abstrato capitalista de base industrial.

Bourdieu (1997, p. 160) descreve como efeito de naturalização este estado que (de)forma e dissimula o espaço quando, por haverem ali características e diferenças sociais determinadas pela lógica histórica; estas acabam, assim, por parecerem surgidas da natureza das coisas. Dessa forma, segundo o filósofo, a inscrição durável das realidades sociais regidas pela posse de capital no "mundo natural" origina esse processo que faz das estruturas sociais fenômenos naturais, ou melhor, das estruturas objetivadas, experiências internalizadas (subjetivas).

Adiciono às análises de Ollman e Bourdieu a visão de Polanyi (2012), que apresenta a problemática da naturalização e autonomia dos fenômenos econômicos sobre as demais esferas da sociabilidade humana, que são assim convertidas em "meros acessórios" dos mercados nas sociedades modernas. Polanyi descreve o processo de desnaturalização da sociedade pela autonomia da economia em um continuum his- 
tórico - ressaltando que, antes da emergência moderna do "sistema oferta-demanda -preço", eram as relaçôes econômicas que se encontravam enraizadas e subordinadas às relações sociais de natureza política, jurídica, religiosa, estética etc. (POLANYI, 2012; BONALDI, 2014).

Dessa forma, o processo de alienaçáo capitalista e de arranjos e disputas pela localização territorial a partir da posse de capital econômico-financeiro une-se à visão de um espaço abstrato que busca dominar e homogeneizar a dinâmica urbana. As periferias urbanas podem ser vistas, assim, como fruto de um processo de produção do espaço abstrato de expropriação que, comandado pela lógica de produção e acumulação capitalista, tende a apagar as diferenças culturais, étnicas e históricas à medida que direciona a localização de uma população urbana de acordo com sua renda, onde o valor de troca sobrepóe-se ao valor de uso da terra urbana.

Quando, pois, é identificado um processo de resistência à tendência homogeneizadora do espaço abstrato, ou um contexto de questionamento da lógica hegemônica produtora do espaço, há, assim, a emergência do espaço diferencial.

Aliado ao conceito lefebvriano de diferença, temos a definição de Furtado (1978) para o "verdadeiro desenvolvimento", o qual, diferentemente da ideia de crescimento econômico, recebe um caráter endógeno, ao ser tido como "expressão da capacidade para criar soluções originais aos problemas específicos de uma sociedade" (FURTADO, 1978, p.80).

Assim, se a lógica do capital industrial tende à atenuação de diferenças e diversidades nas relaçôes sociais de produção e consumo, e o desenvolvimento tem a criatividade e a diversificação como vetores, entendo que focalizar a emergência do urbano utópico nas periferias como recuperação da diversidade se torna fundamento da criação endógena de respostas técnicas, econômicas e institucionais ${ }^{24}$.

França Filho (2008) propóe uma reflexão em torno dos bancos comunitários sob uma perspectiva de antropologia econômica. Ele busca ressaltar algumas características singulares dos bancos que possibilitem situá-los enquanto instância prática de construção, exercício e desenvolvimento do que identifica como uma outra forma de fazer economia. Por esse viés, as moedas sociais são apresentadas pelo autor com vistas a resgatar o sentido antropológico da moeda, como elemento que permite vincular-se a uma totalidade social: "Para além de um simples papel de mediador das trocas, a moeda social deve ser compreendida 'como mediação social e como relação ao grupo como um todo'” (SERVET, $1999^{25}$ apud FRANÇA FILHO, 2008)”.

Tal análise nos permitiria, assim, vislumbrar, na adoção da moeda social, a economia de toda uma área urbana tomar um sentido plural, onde a lógica hegemônica de mercado passa a coexistir com outro sentido da economia, expresso, nesse caso, por laços de domesticidade e solidariedade. Se, para Polanyi (2012), as práticas econômicas de mercado se naturalizam na sociedade à medida que se abstraem e se desenraizam do território - visão da economia como global e totalitária para todo e qualquer povo e lugar -, então o conjunto de açóes do banco comunitário possibilitaria evidenciar uma nova economia em sua dimensáo espacial, ao propor um retorno ao local, ao espaço produzido e vivido a partir de iniciativas da comunidade ali constituída.

Ademais, as moedas sociais poderiam ainda possibilitar, em um espaço urbano específico, um horizonte de realização do reenvolvimento da dimensão de mercado com as instituiçôes sociais locais, entendendo que a separação histórica entre tais di-
24 Tenho como referência para tal constatação o estudo de Silva (2015) que traça as relações entre o uso de recursos e a conservação do bioma no debate sobre o desenvolvimento na Amazônia.

25 SERVET, J. M. et al. (org.). Une économie sans argent - Les systèmes d'échanges locaux. Paris: Éditions du Seuil, 1999. 
mensôes foi o que permitiu a dominação da lógica de mercado sobre as demais esferas da sociabilidade (POLANYI, 2012).

Comumente aliada às demais açôes de desenvolvimento local dos bancos comunitários, a moeda social pode se configurar, dentre muitos outros aspectos, em um elemento demarcador da economia solidária no território. A sua circulação permite um mapeamento entre comerciantes, prestadores de serviço, consumidores e produtores locais, que revela até onde se estende a adesão à nova moeda. Possibilita, assim, uma compreensão preliminar de um processo de diferenciação do espaço em relação às demais áreas urbanas, onde a economia se exerce unicamente na lógica padrão.

Nesse sentido, a busca por utilizar a ideia de fortalecimento de um espaço diferencial na adoção da moeda social tende a ultrapassar o sentido de resistência no processo de transformaçôes para a produção desse "novo" espaço. Há que se pensar, portanto, sobre em que medida as moedas sociais possibilitam uma articulação à lógica monetária e comercial oficial, representando uma nova forma de relacionamento de produção, compra e venda (uma outra economia) e que ao mesmo tempo não se configure em um embate à lógica vigente, como o termo "resistência" pressupóe.

Além disso, para se identificar potenciais aspectos de fortalecimento de um espaço diferencial a partir de medidas como a criação da moeda social, deve-se levar em conta em que medida a comunidade local é o agente definidor desse processo e se este se deu por meio de um questionamento coletivo da lógica hegemônica. Também é preciso avaliar em que medida há uma adesão da população local que permita que tal instrumento induza a novas formas de relaçóes de compra, venda, produção e, mais ainda, de reprodução social.

\section{CONSIDERAÇÕES}

Tendo em vista o caminho de reflexão até aqui traçado, entende-se que, quando há uma experiência coletiva/comunitária de questionar as contradiçôes e a autonomia do sistema monetário (e demais aspectos constituintes da lógica hegemônica), e, a partir daí, são promovidas alteraçôes locais significativas nas relaçôes econômicas, sociais e políticas daquele povo, teríamos, assim, a demarcação de um território onde ganha força a diferença e a criatividade.

Contudo, a simples introdução de uma moeda social não é capaz de evidenciar por si só um desenvolvimento local e tampouco a emergência do urbano lefebvriano na cidade a partir das periferias. $\mathrm{O}$ que se propóe aqui é identificar o potencial de unir a visão de Lefebvre de produção do espaço a uma experiência socioeconômica com significados eminentemente portadores de novos e alternativos horizontes para a práxis urbana.

Programas de pesquisa em torno dessa temática devem, pois, levar em consideração os processos precedentes à criação da moeda e as demais ações comunitárias - que precedem ou que sejam simultâneas - que se relacionam à sua circulação entre os produtores, comerciantes e consumidores locais.

De fato, a criação da moeda Palmas, em Fortaleza, foi precedida de diversas açóes da comunidade local com origem 18 anos antes - a partir da criação da associação de moradores locais (MELO NETO SEGUNDO, 2003). 
Assim, para uma aproximação investigativa em escala local do fenômeno das moedas sociais atreladas aos bancos comunitários, é preciso que se evidenciem aspectos em torno dos laços de coesão urbana precedentes e possivelmente fortalecidos com a instituição da moeda. Deve-se, pois, buscar interfaces entre produtores, comerciantes e consumidores locais, para que seja evidenciado como as relaçôes de bases econômicas se manifestam e em que medida podem essas ser consideradas diferentes das relaçôes econômicas oficiais do mundo capitalista ocidental.

Tanto em investigações em escala nacional - que analisem a rede formada entre os bancos comunitários do país no compartilhamento das metodologias e no suporte institucional e financeiro -, quanto em estudos na escala da dinâmica local - que pesem as dimensóes de produçáo do espaço e dos laços comunitários como aqui é evidenciado -, outro importante aspecto que deve ser levantado em pesquisas de moedas sociais é o modelo instituído em 2015 de substituição da moeda local física (em papel) por um aplicativo de celular de transferência de crédito identificado como "moeda eletrônica", denominado de e-dinheiro, criado por uma empresa privada e posteriormente comprado pela Rede Brasileira de Bancos Comunitários.

Todos os bancos pertencentes à Rede aderiram ao novo instrumento, e, em consequência, é previsto o enfraquecimento e até a exclusão da moeda em papel. O edinheiro permite a oferta de um novo serviço - o pagamento de boletos bancários - e possibilita que o banco tenha ganhos percentuais em cada transação financeira de venda e saque feita pelo aplicativo. Nesse sentido, há que se pensar em que medida aspectos relacionados tanto aos níveis de inclusão tecnológica das comunidades atendidas, quanto à inserção de um mecanismo formulado por uma empresa capitalista - e à diferente forma de abrangência territorial (virtual) da "nova moeda" - podem ameaçar os objetivos da moeda social até entáo propagados de desenvolvimento endógeno de uma localidade urbana. Tais discussóes propóem novos passos na pesquisa que compóe este artigo e apontam horizontes para demais pesquisas que possam ser desenvolvidas em torno do tema.

Nesse sentido, este artigo compõe uma reflexão que dá início a uma pesquisa que prevê levantar e identificar tais aspectos em duas experiências de moedas sociais nas periferias da Região Metropolitana de Belo Horizonte (RMBH), MG: o Banco Esmeraldas, criado em novembro de 2012, no Distrito de Melo Viana, do município de Esmeraldas no vetor oeste da RMBH, que tem como uma das ferramentas a circulação da moeda Esmeraldas em um território delimitado, e o Banco Igarapés, inaugurado em julho de 2016, no município de Igarapé, no vetor sudoeste metropolitano, que tem como moeda local a utilização do aplicativo e-dinheiro.

Nessas localidades, propomos uma imersão investigativa que revele como as relaçóes a partir do uso da moeda podem se manifestar além da compra e venda de produtos e serviços para uma nova forma de dinâmica social comunitária. É previsto, ainda, que sejam evidenciados aspectos em torno dos laços de coesão urbana precedentes e possivelmente fortalecidos com a criação de cada banco local.

Tal pesquisa terá seu enfoque nos efeitos da aplicação da moeda social nessas comunidades, sendo prevista uma leitura que analise em que medida cada uma das experiências é capaz de permitir a leitura de um processo de produçáo espacial em que são fortalecidos laços de diferença e criatividade, passíveis de serem delimitados em uma área urbana específica: a área de circulação da moeda.

De fato, o caráter verdadeiramente endógeno da experiência com moedas sociais 
Gustavo Resgala é graduado em Arquitetura e Urbanismo pela Universidade Federal de Juiz de Fora (UFJF); mestre e doutorando em Arquitetura e Urbanismo pela Universidade Federal de Minas Gerais (UFMG) E-mail: gustavo.resgala@ gmail.com

Artigo recebido em 8 de maio de 2016 e aprovado para publicação em 16 de janeiro de 2017. compreende a capacidade de produzir/comercializar/consumir produtos e prestar/ contratar serviços de forma a reproduzir as diversidades locais como potencial de apropriaçáo do espaço da cidade, ultrapassando, assim, a ideia do desejado crescimento econômico local para alcançar possibilidades também de desenvolvimento político e cultural de sua população, rumo à realização progressiva da sociedade urbana prevista por Lefebvre.

\section{REFERÊNCIAS}

ANDRADE, L. T. O espaço metropolitano no Brasil: nova ordem espacial? Caderno CRH, v. 29, n. 76, p. 101-118, jan./abr. 2016. https://doi.org/10.1590/s010349792016000100007

BONALDI, E. V. Karl Polanyi, A subsistência do homem e ensaios correlatos. Tempo Social, v. 26, n. 1, p. 287-291, jan./jun. 2014. Disponível em: <http://www.scielo.br/pdf/ts/ v26n1/18.pdf>. Acesso em: 20 jan. 2017.

BOURDIEU, P. Efeitos de Lugar. In: __-___-_ (Coord.). A Miséria do Mundo. Petrópolis: Vozes, 1997. p. 159-166.

CANETTIERI, T. A produção das novas periferias metropolitanas: migração e expulsão dos pobres da RMBH na primeira década do século XXI. 2014. 270 f. Dissertação (Mestrado em Geografia) - Programa de Pós-Graduação em Geografia, Pontifícia Universidade Católica de Minas Gerais, Belo Horizonte, 2014. Disponível em: <http://blog.indisciplinar.com/ wp-content/uploads/2014/05/CANETTIERI-Thiago-A-Produ\%C3\%A7\%C3\%A3odas-Novas-Periferias-Metropolitanas.pdf>. Acesso em: 20 jan. 2017.

CASTELLS, M. O poder da identidade. Rio de Janeiro: Paz e Terra, 1999.

COELHO, F. D. Finanças Solidárias. In: CATTANI, A. D. (Org.). A outra economia. Porto Alegre: Veraz Editores, 2003. p. 153-164.

CORAGGIO, J. L. Da Economia dos Setores Populares à Economia do Trabalho. In: KRAYCHETE, G. et al. (Org.). Economia dos setores populares: entre a realidade e a utopia, Petrópolis: Vozes, 2000. p. 91-133.

CORRÊA, R. L. O Espaço Urbano. São Paulo: Ática, 1995.

COSTA, G. M. A Contribuição da Teoria de Espaço de Lefebvre para a análise urbana. In: LIMONAD, E. (Org.). Entre a ordem próxima e a ordem distante: contribuiçôes a partir do pensamento de Henri Lefebvre. Niterói: Ed. GECEL-UFF, 2003. p. 9-14.

. Teorias sócio-espaciais: diante de um impasse? Etc... espaço, tempo e crítica, v. 1, n. 2, jul./ set. 2007. Disponível em: <http://www.uff.br/etc/UPLOADs/etc\%202007_2_2. pdf $>$. Acesso em: 20 jan. 2017.

COSTA, H. S. M; COSTA, G. M. Repensando a análise e a práxis urbana: algumas contribuiçóes da teoria do espaço e do pensamento ambiental. In: DINIZ, C. C.; LEMOS, M. B. (Org.). Economia e Território. Belo Horizonte: Ed. UFMG, 2005. p. 365-382.

FAINSTEIN, S. Justice, politics and the creation of urban space. In: MERRIFIELD, A.; SWYNGEDOUW, E. (Ed.). The urbanization of injustice. New York: New York University Press, 1997. p. 18-44.

FRANÇA FILHO, G. C. Consideraçóes sobre um marco teórico-analítico para a experiência dos Bancos Comunitários. In: SILVA, J. T. J. et.al. (Org.). Gestão Social, Práticas em Debate, Teorias em Construção. Juazeiro do Norte, 2008. p. 117-128.

FREIRE, M. V. Moedas Sociais: contributo em prol de um marco legal e regulatório para as moedas sociais circulantes locais no Brasil. 2011. 374 f. Tese (Doutorado em Direito) -Faculdade de Direito, Universidade de Brasília, Brasília, 2011. Disponível em: <http:// 
repositorio.unb.br/bitstream/10482/9485/1/2011_MarusaVasconcelosFreire.pdf>. Acesso em: 20 jan. 2017.

FURTADO, C. Criatividade e dependência na civilizaçâa industrial. Rio de Janeiro: Paz e Terra, 1978.

GOTTDIENER, M. A produção social do espaço urbano. São Paulo: EDUSP, 1993.

HIROTA, M. Y. La cohesión social, clave para las monedas sociales. El País, Madrid, abr. 2016. Disponível em: <http://elpais.com/elpais/2016/04/11/ alterconsumismo/1460355840_146035.html>. Acesso em: 20 jan. 2017.

KOWARICK, L. A espoliação urbana. Rio de Janeiro: Paz e Terra, 1979.

LAGO, L. C. A "periferia" metropolitana como lugar do trabalho: estrutura sócio-ocupacional e mobilidade cotidiana no Rio de Janeiro. In: LASA INTERNATIONAL CONGRESS, 2009, Rio de Janeiro. Annals... Rio de Janeiro: Latin American Studies Association, 2009.

LEFEBVRE, H. The production of space. Oxford: Blackwell, 1993. $O$ direito à cidade. São Paulo: Centauro, 2008.

MARICATO, E. Globalização e Política Urbana na Periferia do Capitalismo. Revista Veracidade, ano IV, n. 4, mar. 2009. Disponível em: <http://www.veracidade.salvador. ba.gov.br/v4/images/pdf/artigo7.pdf>. Acesso em: 20 jan. 2017.

MARKUSEN, A. R. Região e Regionalismo: Um enfoque marxista. Espaços \& Debates, n. 2, p. 61-99. 1981.

MARQUES, E. Elementos conceituais da segregação, da pobreza urbana e da ação do Estado. In: ; TORRES, H. (Org.). São Paulo - segregação, pobreza e desigualdades sociais. São Paulo: Ed. Senac, 2005. p. 19-56.

; TORRES, H. (Org.). São Paulo - segregação, pobreza e desigualdades sociais. São Paulo: Ed. Senac, 2005.

MELO NETO SEGUNDO, J. J. O Banco de Palmas. In: FUNDAÇÃO LUÍS EDUARDO MAGALHÂES. Economia Solidária: desafios para um novo tempo. Salvador: FLEM, 2003. p. 97-106.

MENDONÇA, J. G.; ANDRADE, L. T.; DINIZ, A. M. A. Introdução: Mudanças e permanências na estrutura socioeconômica e territorial na Região Metropolitana de Belo Horizonte. In: (Org.). Belo Horizonte: transformaçôes na ordem urbana. Rio de Janeiro: Letra Capital: Observatório das Metrópoles; Belo Horizonte: PUC-Minas, 2015. p. 15-32.

MENEZES, M. S. Moedas Locais: uma investigação exploratória sobre seus potenciais como alternativa à exclusão financeira a partir do caso do Banco Bem em Vitória/ES. 2007. 121 f. Dissertação (Mestrado em Economia) - Centro de Desenvolvimento e Planejamento Regional, Universidade Federal de Minas Gerais, Belo Horizonte, 2007. Disponível em: <http://www.bibliotecadigital.ufmg.br/dspace/bitstream/handle/1843/ AMSA-72JJ5Q/disserta__o_melissa_silva_menezes_2007.pdf?sequence $=1>$. Acesso em: 20 jan. 2017.

MONTE-MÓR, R. L. M. Gênese e estrutura da cidade mineradora. Texto para discussão, n. 164, p. 1-14, 2001. Disponível em: <http://www.cedeplar.ufmg.br/pesquisas/td/ TD\%20164.pdf>. Acesso em: 20 jan. 2017.

O cotidiano e a produção do espaço. In: COLÓQUIO DE PESQUISAS EM HABITAÇÃO, 3., 2006, Belo Horizonte. Anais... Belo Horizonte: EA-UFMG, 2006 a. Disponível em: <http://www.mom.arq.ufmg.br/mom/02_eventos/coloquio2006/ palestras/monte-mor.htm>. Acesso em: 20 jan. 2017.

O que é o urbano no mundo contemporâneo. Texto para Discussão, 281, p. 1-14, jan. 2006b. Disponível em: <http://www.cedeplar.ufmg.br/pesquisas/td/TD\%20281.pdf>. Acesso em: 20 jan. 2017. 
MUMFORD, L. A cidade na história. Suas origens, transformaçóes e perspectivas. São Paulo: Martins Fontes, 2008.

MUÑOZ, R. Finanças Solidárias. In: CATTANI, A. D. et al. Dicionário Internacional da Outra Economia. Coimbra: Almedina, 2009. p. 31-36.

NASCIMENTO, A. M. Moeda Palma e o Desenvolvimento Sustentável do Conjunto Palmeiras através da Economia Solidária. 2011. 130 f. Dissertação (Mestrado em Economia) - Faculdade de Economia, Administração, Atuária e Contabilidade, Universidade Federal do Ceará, Fortaleza, 2011. Disponível em: <http://www. repositorio.ufc.br/bitstream/riufc/6213/1/2011_dissert_amnascimento.pdf>. Acesso em: 20 jan. 2017.

NÚCLEO DE ECONOMIA SOLIDÁRIA (NESOL-USP). Banco Palmas 15 anos: resistindo e inovando. São Paulo: A9 Editora, 2013.

OLlmAN, B. Alienation: Marx's Conception of Man in Capitalist Society. Cambridge: Cambridge University Press,1976. Disponível em: <https://www.nyu.edu/projects/ ollman/docs/a_ch18.php>. Acesso em: 20 jan. 2017.

POLANYI, K. A subsistência do homem e ensaios correlatos. Rio de Janeiro: Contraponto, 2012.

RIGO, A. S. Moedas sociais e bancos comunitários no brasil: aplicaçôes e implicações, teóricas e práticas. 2014. 344 f. Tese (Doutorado em Administração) - Escola de Administração, Universidade Federal da Bahia, Salvador, 2014. Disponível em: <http://www. adm.ufba.br/sites/default/files/publicacao/arquivo/tese_versaofinalcompleta_para_ impressao_final.pdf>. Acesso em: 20 jan. 2017.

SANTOS, L. L.; SILVA, B. C. Mercados de trocas e moedas sociais em Portugal continental: os desafios de uma cultura de emancipação social. Otra Economía, v. 8, n. 15, p. 210-219, jul./dez. 2014. https://doi.org/10.4013/otra.2014.815.08

SILVA, H. Cidades, urbanização, desenvolvimento na Amazônia: notas para uma interpretação lefebvriana. In: COSTA, G. M.; COSTA, H. S. M.; MONTE-MÓR, R. L. M. (Org.). Teorias e práticas urbanas: condições para a sociedade urbana. Belo Horizonte: C/Arte, 2015. p. 317-342.

SINGER, P. I. O uso do solo urbano na economia capitalista. In: MARICATO, E. (Org.). A produção capitalista da casa (e da cidade) no Brasil industrial. São Paulo: Alfa-Omega, 1979. p. 21-36.

- Economia dos Setores Populares: propostas e desafios. In: KRAYCHETE SOBRINHO, G. (Org.). Economia dos Setores Populares: entre a realidade e a utopia. Petrópolis: Vozes, 2000. p. 143-161.

. A recente ressurreição da economia solidária no Brasil. In: SANTOS, B. S. (Org.). Produzir para viver: os caminhos da produção não capitalista. Rio de janeiro: Civilização Brasileira, 2002. p. 81-129.

. Finanças solidárias e moeda social. In: FELTRIM, L. E.; VENTURA, E. C. F.; DOLD, A. V. B. Projeto inclusão financeira. Brasília: Banco Central do Brasil, 2009. p. 69-78.

. O Banco Comunitário de Desenvolvimento como política pública de economia solidária. In: NÚCLEO DE ECONOMIA SOLIDÁRIA - NESOL-USP. Banco Palmas 15 anos: resistindo e inovando. São Paulo: A9 Editora, 2013. p. 35-40.

SOARES, C. L. B. Moeda social - uma análise interdisciplinar de suas potencialidades no Brasil Contemporâneo. 2006. 251 f. Tese (Doutorado em Ciências Humanas) Centro de Filosofia e Ciências Humanas, Universidade Federal de Santa Catarina, Florianópolis, 2006. Disponível em: <https://repositorio.ufsc.br/bitstream/ handle/123456789/89433/226267.pdf?sequence=1\&isAllowed=y>. Acesso em: 20 jan. 2017. 
SOJA, E. A dialética Sócio-espacial. In: Geografias pós-modernas: a reafirmação do espaço na teoria social crítica. Rio de Janeiro: Zahar, 1993. p. 97-116.

Postmetropolis: critical studies of cities and regions. Malden, MA: Blackwell Published, 2000.

TAFURI, D. M. Bancos Comunitários no contexto contemporâneo das periferias brasileiras. Revista do IMEA-UNILA, v. 2, n. 1, p. 49-60, 2014. Disponível em: <https://revistas. unila.edu.br/index.php/IMEA-UNILA/article/view/259>. Acesso em: 20 jan. 2017.

TONUCCI, J. B. M. Cidade fractal: transformaçóes recentes na Região Metropolitana De Belo Horizonte. In: ENCONTRO NACIONAL DA ANPUR, 13., 2009, Florianópolis. Anais... Florianópolis: ANPUR, 2009. Disponível em: <http://unuhospedagem. com.br/revista/rbeur/index.php/anais/article/view/3226>. Acesso em: 20 jan. 2017.

TOPALOV, C. Fazer a história da pesquisa urbana: a experiência francesa desde 1965. Espaços \& Debates, v. 1, n. 23, p. 05-30, 1988. 